\title{
LEGISLAÇÃO RESTRITIVA REFERENTE AO USO DE AGROTÓXICOS EM MUNICÍPIOS DO ESTADO DO PARANÁ
}

\author{
RESTRICTIVE LEGISLATION REGARDING THE USE OF PESTICIDES IN PARANA CITIES
}

\author{
Roberto de Resende Lisboa Piassetta ${ }^{1}$, Nilton José Souza², Ana Paula Mikos ${ }^{3}$, Celso Garcia Auer ${ }^{4}$ \\ 1,2,3 Universidade Federal do Paraná, Curitiba, Paraná, Brasil-robertopiassetta@gmail.com, \\ anapaulamikos@hotmail.com \&nilton.ufpr@gmail.com \\ ${ }^{4}$ Embrapa Florestas, Colombo, Paraná, Brasil - celso.auer@embrapa.com
}

\begin{abstract}
RESUMO
O estado do Paraná é um dos maiores consumidores de agrotóxicos por hectare plantado do Brasil devido a sua grande produção agrícola. Apesar da necessidade do uso de agrotóxicos para atender a demanda de alimentos, estes podem causar danos ao meio ambiente e à saúde. Por isso, existem legislações que regulam, fiscalizam e controlam o uso indiscriminado de produtos que possam causar riscos. $\mathrm{O}$ objetivo do presente trabalho foi realizar um levantamento das legislações proibitivas ou restritivas referentes ao uso de agrotóxico nos 399 municípios do Paraná. As legislações foram obtidas através dos sites das prefeituras e câmaras municipais para análise comparativa. As leis foram classificadas quanto ao ano, tipo de lei e tipo de restrição. O tipo de lei foi dividido entre municipal, complementar, ordinária e orgânica, e o tipo de restrição em perímetro urbano e rural, tipos de produto, pulverização aérea e áreas especiais. Foram encontradas 103 leis em 100 municípios com restrição ou proibição quanto ao uso de agrotóxicos. A maioria das leis restringe o uso de agrotóxicos no perímetro urbano e delimitam uma distância mínima para aplicação na área rural. Também foram encontradas leis com restrições ao uso de classes de agrotóxicos, como o herbicida 2,4 D, e relacionadas a pulverização aérea.
\end{abstract}

Palavras-chaves: Agrotóxico, Herbicida, Legislação, Paraná, Pulverização aérea.

\section{ABSTRACT}

Paraná state is currently one of the largest consumers of agrotoxics per hectare planted in Brazil due to its large crop agricultural. Agrotoxics are needed in the agricultural sector to allows to attend the food demand. However, they can cause damage to the environment and human and animal health. There is a gap in the Brazilian laws to regulate, supervise and control the use of chemical products, and its indiscriminate products that may cause risks. The present research aims to survey the prohibitive or restrictive laws related to the use of agrotoxics in the 399 cities of the Paraná state. The legislations were obtained through the websites of city halls and city councils and it was performed a comparative analysis. The laws were classified according to year, type of law and type of restriction. The type of law was divided into municipal, complementary, ordinary and organic. The type of restriction was divided in urban and rural perimeter, product types, aerial spraying and special areas. It was found 103 laws, 100 cities with some restriction or ban on the use of pesticides in their territory. The majority restrictive laws use within the urban perimeter and delimit a minimum distance from the perimeter that can be applied in the rural area. There are also laws with restrictions on the use of pesticide classes, such as $2.4 \mathrm{D}$ herbicide, and related to aerial spraying.

Keywords: Agrotoxic, Herbicid, Legislation, Paraná, Aerial spraying. 


\section{INTRODUÇÃO}

No Brasil, o regulamento da Defesa Sanitária Vegetal aprovada pelo Decreto no 24.114 de 1934, foi o primeiro mecanismo que abordou a fiscalização de inseticidas e fungicidas com aplicação na lavoura (BRASIL, 1934). Em 1976, o Ministério da Saúde passou a controlar o registro dos produtos químicos e a partir do ano de 1982, as legislações estaduais sobre uso, comercialização e distribuição dos agrotóxicos começaram a ser aprovadas. Em 1988, a Constituição Federal atribuiu a competência concorrente entre a União e os Estados referente a florestas, caça, pesca, fauna conservação da natureza, defesa do solo e dos recursos naturais, proteção do meio ambiente e controle da poluição, além da responsabilidade por dano ao meio ambiente e ao consumidor (BRASIL, 1988).

A Lei Federal no 7.802, de 11 de julho de 1989, é a principal lei que dispõe sobre agrotóxicos no Brasil (BRASIL, 1989). Em 1990, o Decreto no 98.816 (substituído pelo Decreto $n^{\circ} 4.074$, de 2002) atribuiu a competência aos estados para legislar e fiscalizar especificamente sobre o tema agrotóxico, do mesmo modo como o município pode legislar supletivamente sobre o uso de agrotóxicos (BRASIL, 2002).

A Instrução Normativa no 2, de 2008, apresenta as normas para aplicação de agrotóxicos por avião agrícola. Não é permitida a aplicação aérea de agrotóxicos em áreas situadas a uma distância mínima de $500 \mathrm{~m}$ de povoações, cidades, vilas, bairros, de mananciais de captação de água para abastecimento de população e $\mathbf{2 5 0} \mathrm{m}$ de mananciais de água, moradias isoladas e agrupamentos de animais (BRASIL, 2008).

Estes instrumentos legais regulamentam no Brasil o uso de 405 ingredientes ativos registrados como agrotóxicos, que dão origem a 2455 produtos formulados para venda no mercado. Dentre eles, $25 \%$ são herbicidas, $21 \%$ são inseticidas, $22 \%$ são fungicidas, e os demais englobam acaricidas, adjuvantes e reguladores de crescimento (AGROFIT, 2020). Em relação à venda de agrotóxicos em 2019 por classe de uso, os herbicidas se destacaram com 59,6\%, fungicidas com $15,2 \%$ e os inseticidas com $11,7 \%$ das vendas, totalizando mais de 620 mil toneladas de ingredientes ativos comercializados (IBAMA, 2020).

No Paraná, o Decreto Estadual no 3.876, de 1983 dispõe sobre distribuição e comercialização de agrotóxicos e outros biocidas no território, e ainda proíbe o uso de agrotóxicos organoclorados (PARANÁ, 1983).

A Resolução SEIN no 022, de 05 de julho de 1985, diz respeito à proteção do meio ambiente e recursos hídricos relativos ao controle da poluição por agrotóxicos e biocidas no território estadual (PARANÁ, 1985). A resolução do SEIN apresenta as mesmas diretrizes da Instrução Normativa no 2 de 2008, em relação às distâncias mínimas para aplicação aérea de agrotóxicos. Porém, a resolução estadual ainda restringe a aplicação de agrotóxicos com o tipo de equipamento, permitindo a aplicação de agrotóxicos e biocidas nas lavouras, se efetuada por atomizadores ou canhões, numa distância mínima de 250 m, e, por aparelhos costais ou tratorizados de barra, numa distância mínima de $50 \mathrm{~m}$.

Em complemento, a Resolução SESA nº 446 de 2016, dispõe sobre a proibição de utilização de mecanismos para controle vetorial por meio de dispersão de agrotóxicos por aeronaves em áreas urbanas no estado do Paraná. O Art. 10 indica: "Proibir a utilização de mecanismos de controle vetorial por meio de dispersão de agrotóxicos por aeronave (pulverização aérea) em áreas urbanas no estado do Paraná" (PARANÁ, 2016).

No Paraná, a atividade agrícola é a que ocupa a maior extensão territorial do estado, com $83 \%$ de sua área ocupada por lavoura e pastagens. As culturas com maior utilização de agrotóxicos no Paraná no ano de 2018 foram soja (57\%), milho (17,3\%) e trigo (3,6\%) (SIAGRO, 2018). A quantidade média de agrotóxicos usada no estado em 2015 foi de 8,25 kg/ha. Em relação à classe de uso, houve destaque para os herbicidas, utilizados principalmente no controle de ervas daninhas, correspondente a $55 \%$ do total dos agrotóxicos mais utilizados (IPARDES, 2017).

Diante deste contexto, o objetivo geral deste trabalho foi realizar um levantamento da legislação referente à proibição e restrição do uso de agrotóxicos nos 399 municípios do estado do Paraná. Os objetivos específicos foram: determinar os municípios que possuem instrumentos legais restritivos ao uso de agrotóxicos; classificar a legislação quanto ao tipo (lei municipal, complementar, ordinária, orgânica, etc.); identificar o tipo de restrição associada aos instrumentos legais avaliados (área urbana/rural, tipo de agrotóxico, pulverização aérea, áreas especiais, recursos hídricos); comparar as leis em nível municipal, estadual e federal; e elaborar um mapa que identifique as regiões do estado do Paraná que apresentam a maior concentração da legislação restritiva ao uso de agrotóxicos.

\section{MATERIAL E MÉTODOS}

Para a elaboração deste trabalho, foi realizado um levantamento das leis que restringem ou proíbem o uso de 
agrotóxicos nos municípios do estado do Paraná. O estado do Paraná se localiza na região Sul do Brasil e apresentou em 2019 uma área total de 199.298,979 km² e uma população estimada em 2020 de 11.516 .840 habitantes (IBGE, 2020). O Paraná está dividido em 399 municípios, que podem ser distribuídos em 6 regiões (Centro-oeste, Litoral, Noroeste, Norte, Oeste e Centro-sul), com um total de 22 núcleos estabelecidos pela Secretaria de Estado da Agricultura e do Abastecimento (SEAB), como indica a Figura 1.

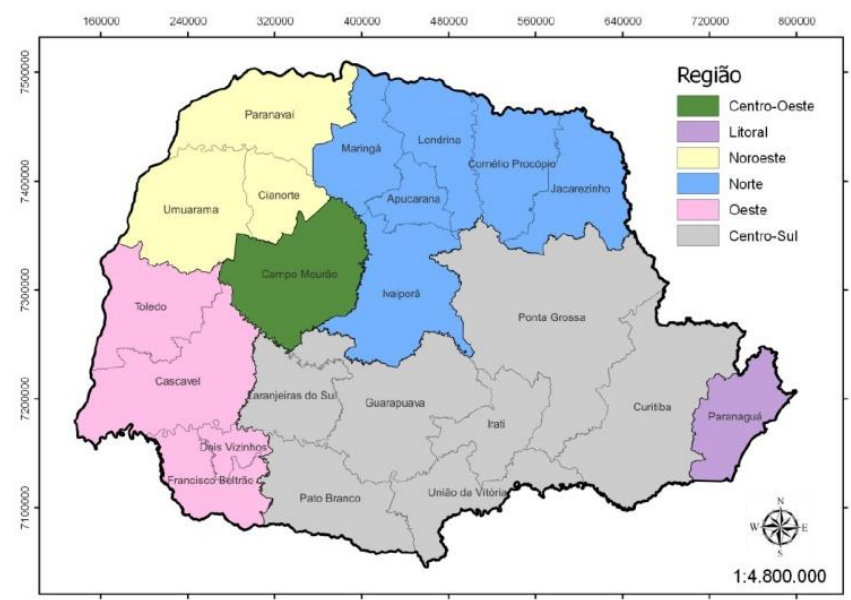

Figura 1. Regiões e núcleos regionais no estado do Paraná (EISFELD \& NASCIMENTO, 2015).

Para a obtenção das leis que restringem ou proíbem o uso de agrotóxicos nos municípios do Paraná, foram realizadas consultas nos sites das prefeituras e câmaras de vereadores, buscando leis que abordavam este tema em seus respectivos municípios. As palavras-chaves para pesquisa foram: "agrotóxicos", "herbicida", "pulverização", "pulverização aérea", "defensivos", "agroquímicos" e "produtos químicos". A coleta de dados ocorreu entre os meses de fevereiro e maio de 2018. Após - levantamento das leis proibitivas relacionadas aos agrotóxicos dos municípios, as leis foram classificadas quanto ao ano de publicação, tipo de lei e tipo de restrição.

A análise do ano de publicação foi realizada de modo a entender se existe algum período com maior frequência de criação de leis. As leis foram classificadas quanto ao tipo: lei municipal, lei complementar municipal, lei ordinária municipal e lei orgânica municipal. A classificação quanto ao tipo de restrição foi: área urbana, área rural, tipos de produtos (herbicida, inseticida, fungicida e outros), pulverização aérea, áreas especiais (Área de Proteção Ambiental - APA e Área de Preservação Permanente - APP), mananciais hídricos. As leis municipais também foram comparadas com a Legislação Federal (Instrução Normativa MAPA no 2/08) e estadual referente à agrotóxicos (RESOLUÇÃO SEIN no 022/85).

\section{RESULTADOS E DISCUSSÃO}

Dentre os 399 municípios do Paraná, foram encontradas 103 leis no total, em 100 municípios, sendo que foram encontrados ao menos um instrumento legal que restringe ou proíbe o uso de agrotóxico. Três dos 100 municípios avaliados (Cascavel, Marilândia do Sul e Rancho Alegre) possuíam duas leis diferentes abordando o tema agrotóxico. Nos demais 299 municípios não foram encontrados instrumentos legais com proibição ou restrição ao uso de agrotóxicos, somente leis que regulamentam e seguem as instruções das leis federais e estaduais.

A classificação das leis encontradas nos municípios do estado do Paraná é apresentada na Figura 2 através de um organograma, para melhor visualização dos dados utilizados no presente trabalho.

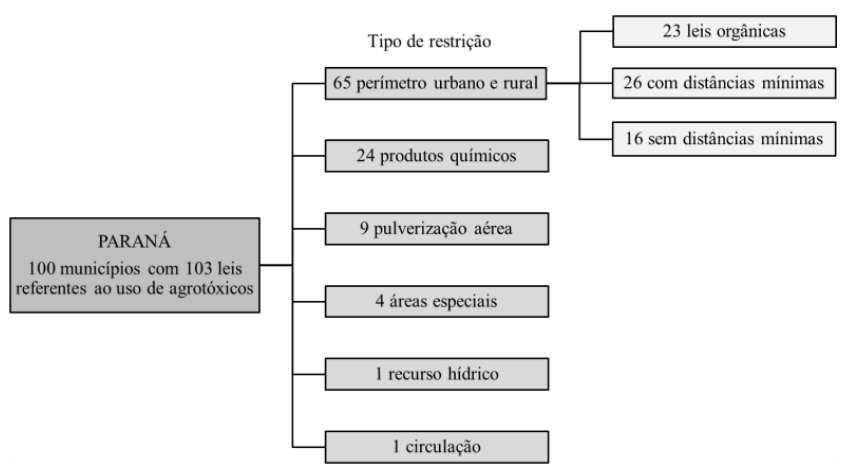

Figura 2. Organograma das leis encontradas no estado do Paraná

As regiões que mais se destacaram por apresentarem legislação restritiva sobre o tema de agrotóxicos foram à região Norte e a região Centro-oeste, com 34\% e $46 \%$, respectivamente de seus municípios com leis. Na região Norte, os núcleos com maior frequência de legislação foram Apucarana e Ivaiporã e o núcleo de Campo Mourão da região Centro-oeste. Uma visão geral dos 100 municípios do Paraná que apresentaram legislações sobre alguma proibição ou restrição relacionada a agrotóxicos é mostrada na Figura 3.

É possível perceber que nos grandes polos agrícolas localizados nos núcleos regionais de Cascavel, Maringá e Londrina, os municípios apresentaram algum tipo de lei restritiva ou proibitiva referente ao uso de agrotóxicos. 0 núcleo de Cascavel também apresenta alto consumo de agrotóxicos por hectare, mesmo com legislações restritivas, pois a forte vocação agrícola desta região faz 
com que o consumo deste tipo de insumo seja elevado.

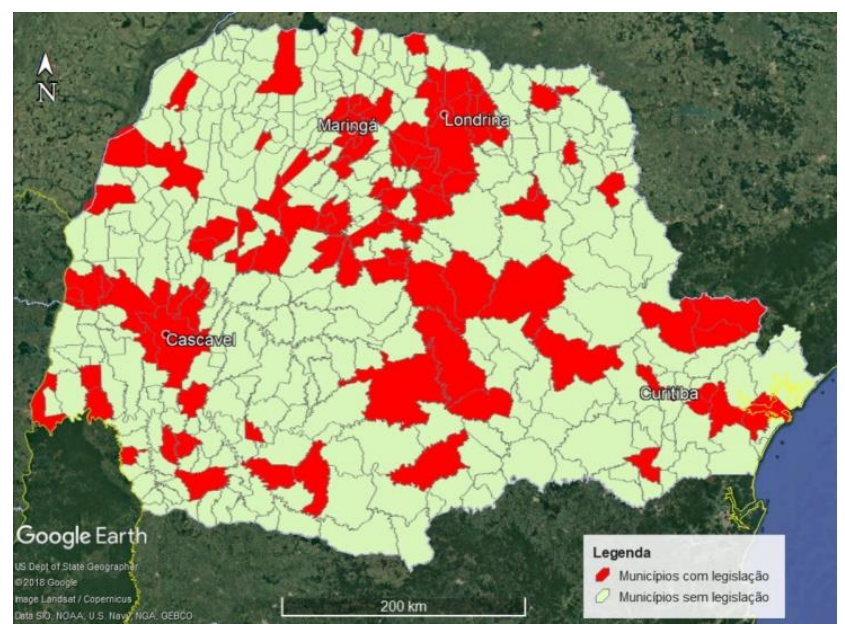

Figura 3. Municípios do estado do Paraná com legislação referente à agrotóxicos.

Além disso, segundo o SIAGRO (2018), os municípios com maior volume comercializado de agrotóxico em 2018 foram em ordem decrescente: Cascavel, Guarapuava, Tibagi, Castro, Toledo, Assis Chateaubriand, Candói, Palmeira, Ponta Grossa e Palotina. Destes municípios, seis pertencem à região Centro-Sul e quatro da região Oeste. Vale ressaltar, entre os dez municípios com maior venda de agrotóxico, apenas cinco cidades (Cascavel, Guarapuava, Tibagi, Toledo e Ponta Grossa) possuem algum tipo de legislação restritiva quanto ao uso de agrotóxico. O volume comercializado destes municípios variou entre 1.020 a 1.873 toneladas de agrotóxico no ano de 2018. Não foi possível estabelecer nenhum padrão das leis em relação à região, volume comercializado, disposição geográfica ou área dos municípios.

\section{Classificação quanto ao ano}

As legislações restritivas relacionadas ao uso de agrotóxicos foram classificadas e ordenadas quanto ao ano de publicação. Foi possível identificar que as leis mais antigas foram publicadas no ano de 1990, nos municípios de Assaí e Santa Cruz de Monte Castelo. Ambas são leis orgânicas e com a mesma restrição: “É vedada a implantação de cultura que demande aplicação de agrotóxicos na área rural marginal à área urbana, cuja extensão será definida em lei". Por outro lado, a lei mais recente encontrada no período da pesquisa foi de 2018 do município de Ariranha do Ivaí, a qual proíbe a aplicação de agrotóxico na área urbana, distritos e vila rural.

Entre o período de 1996 a 2000 observou-se que 11 das 14 leis aprovadas foram sobre a utilização do herbicida 2,4-D e somente a partir de 2001 foram criadas leis com algum tipo de proibição contra pulverização aérea de agrotóxicos. Entre os anos de 1991 e 1994 e em 2010, nenhum dispositivo legal foi aprovado restringindo ou proibindo o uso de agrotóxicos nos municípios do Paraná. Também é possível perceber que a partir do ano de 2007 a quantidade de leis por ano aumentou, provavelmente pela crescente preocupação com os prováveis danos causados pelo uso agrotóxicos.

\section{Classificação quanto ao tipo de lei}

No total, foram 103 instrumentos legais avaliados, divididos em leis municipais (50\%), orgânicas (22\%), ordinárias (16\%) e complementares (12\%). A lei municipal é uma ferramenta central do planejamento das cidades do Brasil e pode ser elaborada pela Prefeitura (poder executivo) ou pela Câmara de Vereadores (poder legislativo), e estabelece regras, parâmetros, incentivos e instrumentos para o desenvolvimento do município. A lei orgânica é considerada uma das leis mais importantes que regem os municípios e é considerada a "Constituição" do município, e consiste em uma lei ordinária aprovada em dois turnos pela Câmara Municipal, e pela maioria de dois terços dos membros.

A lei complementar e a lei ordinária são normativas primárias que têm o objetivo de complementar a constituição: explicando, adicionando ou complementando algum assunto constitucional. As principais diferenças entre elas são relacionadas ao quórum de aprovação e a matéria. A lei complementar necessita ser aprovada por maioria absoluta (mais da metade de todos os membros), enquanto a lei ordinária é aprovada pela maioria simples (mais da metade dos presentes). Em relação à matéria, que é o assunto a ser tratado, a lei complementar é exigida em matérias previstas pela Constituição Federal. Por outro lado, a lei ordinária é exigida de modo residual, ou seja, pode abordar qualquer matéria, nos casos em que não há expressa a exigência da lei complementar.

\section{Restrições no perímetro urbano e rural}

Das 103 leis restritivas relacionadas à utilização de agrotóxicos, 65 correspondem à limitação da aplicação de agrotóxicos no perímetro urbano. Entre elas, 23 municípios dispõem de leis orgânicas, sendo que destes, 21 municípios (Araruna, Assaí, Bela Vista do Paraíso, Califórnia, Cambé, Curiúva, Faxinal, Figueira, Jataizinho, Londrina, Manoel Ribas, Marilândia do Sul, Maringá, Mauá da Serra, Porecatu, Rancho Alegre, Santa Cruz de Monte Castelo, 
Santa Inês, Sulina, Tamarana e Wenceslau Braz) dispõem uma redação muito semelhante entre si. As leis orgânicas apresentam a seguinte frase: "É vedada a implantação de cultura que demande aplicação de agrotóxicos na área rural marginal à área urbana, cuja extensão será definida em lei". Cabe salientar que todas as 23 leis orgânicas encontradas se referem ao tema abordado nesse item.

Os municípios de Califórnia, Porecatu e Wenceslau Braz complementam o artigo da lei orgânica do município, com a vedação da classe de uso e aplicação de produtos de alta toxicidade em qualquer propriedade agrícola do município, sem o acompanhamento de profissional habilitado. A cidade de Mauá da Serra também limita o uso de agrotóxicos sem a presença de profissional habilitado. Dos 23 municípios avaliados, duas cidades apresentam artigos diferenciados das leis orgânicas das demais cidades. O Município de Quarto Centenário proíbe aplicação de agrotóxicos não autorizados pela entidade competente e em Salto do Lontra a lei cita que deve ser evitado o uso de agrotóxicos na execução de trabalho de higiene e limpeza pública na área urbana.

Além das leis orgânicas encontradas, também foram identificados 16 municípios que apresentaram leis restritivas ao uso de agrotóxicos em determinados espaços, porém sem especificar as distâncias mínimas. Sete municípios (Conselheiro Mairinck, Entre Rios do Oeste, Goioerê, Indianópolis, Mamborê, Pato Bragado e Quatro Pontes) abordam na legislação municipal, com 3 leis municipais e 4 leis complementares, a proibição de agrotóxico na área urbana. Destes, três municípios (Entre Rios do Oeste, Pato Bragado e Quatro Pontes) também proíbem a aplicação de agrotóxico na área suburbana, que é definida em lei.

Seis municípios (Cambira, Cândido de Abreu, Cascavel, Francisco Beltrão, Grandes Rios e Janiópolis) apresentaram em suas leis municipais o veto ao uso e aplicação de qualquer tipo de agrotóxico na proximidade de estabelecimentos dos municípios. Além disso, frequentemente são indicados nas leis espaços como escolas e colégios, centros municipais de educação infantil, unidades básicas de saúde, unidades de saúde da família e núcleos residenciais da área rural.

O município de Astorga aborda a restrição do uso de agrotóxicos em áreas urbanas e também nas proximidades de cursos d'água e mananciais de captação de água para abastecimento com lei complementar. O município de Irati, além de restringir o uso de agrotóxicos nos recursos hídricos, a lei municipal também restringe sua aplicação em área de preservação permanente (APP).

A cidade de Ivatuba possui uma lei municipal que proíbe a aplicação de agrotóxicos com máquinas agrícolas de tração motorizada ou por reboque com trator, nas culturas de soja, milho e trigo, dentro do perímetro urbano, permitindo o uso apenas na região denominada vila rural.

As leis possuem definições quanto à suas áreas de perímetro urbano e rural, porém não são indicadas quais as distâncias mínimas a serem respeitadas desses locais quanto a aplicação de agrotóxicos. Quando não é apresentada uma distância mínima na lei municipal, devese obedecer às leis superiores como estaduais e federais, que definem as distâncias mínimas a serem respeitadas, bem como técnicas de aplicação.

A Resolução SEIN no 022 indica distâncias para aplicação de agrotóxicos e biocidas em lavouras. $\mathrm{Na}$ referida resolução é atribuída uma distância mínima de 250 $\mathrm{m}$ se a aplicação for realizada com atomizadores ou canhões e $50 \mathrm{~m}$ para aplicação efetuada com pulverizador costal ou tratorizada, de mananciais de captação de água para abastecimento de populações, núcleos populacionais, escolas, habitações e locais de recreação, moradias isoladas e agrupamento de animais e culturas suscetíveis a danos (PARANÁ, 1985).

De acordo com Costa (2009), os pulverizadores pneumáticos, também denominados atomizadores ou canhões, se diferenciam dos hidráulicos (costal, tratorizado ou de barra) pela presença de um ventilador que tem função de gerar uma corrente de ar para levar as gotas até o alvo, com consequente maior perda de produto quando comparada com equipamentos hidráulicos. Por isso, a Resolução SEIN no 022/85 apresenta uma distância mínima menor (50 m) para aplicação com pulverizador costal ou tratorizada, e $200 \mathrm{~m}$ a mais para atomizadores ou canhões (PARANÁ, 1985).

Dentre as demais cidades do Paraná, 26 municípios apresentaram leis que regulamentam as distâncias mínimas para aplicação de agrotóxicos. Sete municípios apresentaram especificação de tecnologia de aplicação, dentro de suas restrições na lei. Dois deles (Campo Mourão e Mangueirinha) permitem a utilização das principais tecnologias de aplicação de agrotóxico: costal manual, costal motorizado, tratorizado com barra, atomizadores e canhões. Três municípios (Adrianópolis, Alto Paraíso e Tunas do Paraná) regulamentam a utilização de bomba costal e tratorizado, e duas cidades (Foz do Iguaçu e Umuarama) permitem apenas o uso de equipamento costal manual.

Dos 26 municípios analisados nesse tópico, 15 apresentaram distâncias mínimas em acordo com a Resolução SEIN n. 022/85 (Alto Paraíso, Apucarana, 
Ariranha do Ivaí, Bandeirantes, Foz do Iguaçu, Jardim Alegre, Medianeira, Morretes, Pérola d'Oeste, Reserva, São Sebastião da Amoreira, Serranópolis do Iguaçu, Sertanópolis, Tunas do Paraná e Umuarama) e 11 apresentaram alguma divergência. A Tabela 1 apresenta as distâncias indicadas nas leis dos municípios em relação às distâncias mínimas para aplicação de agrotóxico. Os itens sublinhados que apresentam alguma divergência em relação à essa Resolução SEIN.

Tabela 1. Divergências nas legislações restritivas ao uso de agrotóxicos.

\begin{tabular}{|c|c|}
\hline Município & $\begin{array}{l}\text { Distância mínima de aplicação de } \\
\text { agrotóxico a ser respeitada pela lei } \\
\text { municipal }\end{array}$ \\
\hline Adrianópolis & $\begin{array}{c}500 \mathrm{~m} \text { do perímetro urbano } \\
100 \mathrm{~m} \text { de mananciais hídricos } \\
\text { Em lavouras: } 250 \mathrm{~m} \text { de imóvel residencial } \\
\text { com aparelhos costais ou tratorizados de } \\
\text { barra }\end{array}$ \\
\hline Anahy & $200 \mathrm{~m}$ do perímetro urbano \\
\hline Barbosa Ferraz & $200 \mathrm{~m}$ do perímetro urbano \\
\hline Campo Mourão & $\begin{array}{l}100 \text { m do perímetro urbano com } \\
\text { equipamento de aplicações costal manual, } \\
\text { costal motorizado, tratorizado com barra, } \\
\text { atomizadores e canhões }\end{array}$ \\
\hline Cerro Azul & $\begin{array}{l}500 \text { m do perímetro urbano } \\
100 \mathrm{~m} \text { de mananciais hídricos }\end{array}$ \\
\hline Ibiporã & $100 \mathrm{~m}$ do perímetro urbano \\
\hline Mangueirinha & $\begin{array}{c}\text { Perímetro urbano e mananciais hídricos } \\
50 \mathrm{~m} \text { (atomizadores e canhões) } \\
25 \mathrm{~m} \text { (aparelhos costais ou barras } \\
\text { tratorizados) }\end{array}$ \\
\hline Prudentópolis & $\begin{array}{l}250 \mathrm{~m} \text { do perímetro urbano } \\
100 \mathrm{~m} \text { de mananciais hídricos }\end{array}$ \\
\hline $\begin{array}{c}\text { Santa Izabel } \\
\text { do Oeste }\end{array}$ & $200 \mathrm{~m}$ do perímetro urbano \\
\hline Tibagi & $200 \mathrm{~m}$ do perímetro urbano \\
\hline Toledo & $\begin{array}{l}250 \mathrm{~m} \text { do perímetro urbano } \\
100 \mathrm{~m} \text { de mananciais hídricos }\end{array}$ \\
\hline
\end{tabular}

O município de Mangueirinha foi o único que apresentou distâncias mínimas de aplicação de produtos em discordância com a Resolução SEIN n. 022/85, tanto para atomizadores e canhões, quanto para equipamento costal ou tratorizado. Uma vez que deve ser observada uma distância mínima de 250 m se a aplicação for realizada com atomizadores ou canhões e $50 \mathrm{~m}$ para aplicação efetuada com pulverizador costal ou tratorizada (PARANÁ,
1985). Os demais municípios (Adrianópolis, Anahy, Barbosa Ferraz, Campo Mourão, Cerro Azul, Ibiporã, Prudentópolis, Santa Izabel do Oeste, Tibagi e Toledo) apresentam distâncias mínimas, porém não indicam a técnica de aplicação. Desse modo, as leis municipais apresentam valores dentro dos parâmetros da lei estadual (50 m) para aplicação de agrotóxico com modalidade costal ou tratorizada. No entanto, se a aplicação for realizada com atomizadores e canhões, as distâncias mínimas são inferiores à $250 \mathrm{~m}$, valor apresentado pela Resolução SEIN n. 022/85 para essa modalidade de aplicação.

A interpretação da lei deve ser referente ao tipo de equipamento utilizado para a aplicação do agrotóxico. Além disso, cabe salientar a importância da Resolução SEIN n. 022/85, uma vez que esta pode ser utilizada como base, tanto para as leis municipais que não apresentaram distâncias específicas, quanto para os municípios que não possuem nenhum dispositivo legal com distâncias específicas para aplicação de agrotóxicos.

\section{Restrição aos produtos químicos}

Dos 100 municípios com leis restritivas avaliadas, 24 apresentaram restrição à algum tipo de agrotóxico, sendo que 22 restringem o uso de herbicidas e em dois o uso de inseticidas (Tabela 2). Em relação aos municípios que restringem a aplicação de herbicidas, constatou-se que em 19 a restrição é referente ao uso de herbicidas derivados de sal dimetilamina do ácido 2,4- diclorofenoxiacético (2,4D), herbicida do grupo dos fenoxiacéticos.

Oito cidades (Cruz Machado, Iretama, Kaloré, Lidianópolis, Mandaguaçu, Marechal Cândido Rondon, Marilândia do Sul e Uraí) proíbem o uso do herbicida 2,4-D em todo o seu território municipal. Três municípios apresentam a restrição a esse herbicida somente em determinados períodos do ano, sendo de setembro a fevereiro para o município de Coronel Vivida, entre agosto e maio no município de Terra Boa e entre setembro e março para a cidade de Corumbataí do Sul. O município de Corumbataí do Sul ainda restringe a aplicação do herbicida a 5.000 m de lavouras sensíveis, tais como: café, amoreira, feijão algodão, hortas e pomares domésticos e comerciais. Os demais municípios (Ângulo, Iguaraçu, Itambé, Juranda, Marialva, Moreira Sales, Nova Tebas e Wenceslau Braz) restringem a aplicação do herbicida 2,4-D à uma distância do perímetro urbano e/ou culturas sensíveis, com variação de 200 a $20.000 \mathrm{~m}$.

Cafelândia, Paranaguá e Sarandi vedam a utilização de qualquer tipo de herbicida na capina química, limpeza ou manutenção de qualquer propriedade ou espaço público 
na aérea urbana. Cafelândia, ainda restringe a aplicação de capina química a $200 \mathrm{~m}$ do perímetro urbano.

Tabela 2. Municípios com restrições à produtos químicos.

\begin{tabular}{|c|c|}
\hline Município & Restrição \\
\hline Ângulo & $2,4 \mathrm{D}-5.000 \mathrm{~m}$ de culturas sensíveis \\
\hline Coronel Vivida & $\begin{array}{c}\text { 2,4 D - Aplicação entre setembro e } \\
\text { fevereiro }\end{array}$ \\
\hline Corumbataí do Sul & $\begin{array}{l}\text { 2,4 D - Aplicação entre setembro e } \\
\text { março e } 5.000 \text { m de lavouras sensíveis }\end{array}$ \\
\hline Cruz Machado & 2,4 D - Todo o município \\
\hline Iguaraçu & $2,4 \mathrm{D}-2.000 \mathrm{~m}$ do perímetro urbano \\
\hline Iretama & 2,4 D - Todo o município \\
\hline Itambé & 2,4 D - $500 \mathrm{~m}$ de parreiras de uva \\
\hline Juranda & $2,4 \mathrm{D}-5.000 \mathrm{~m}$ do perímetro urbano \\
\hline Kaloré & 2,4 D - Todo o município \\
\hline Lidianópolis & 2,4 D - Todo o município \\
\hline Mandaguaçu & 2,4 D - Todo o município \\
\hline $\begin{array}{l}\text { Marechal Cândido } \\
\text { Rondon }\end{array}$ & 2,4 D - Todo o município \\
\hline Marialva & 2,4 D - $20.000 \mathrm{~m}$ de culturas sensíveis \\
\hline Marilândia do Sul & 2,4 D - Todo o município \\
\hline Moreira Sales & $\begin{array}{l}2,4 \mathrm{D}-5.000 \text { m período urbano e } \\
\text { culturas sensíveis }\end{array}$ \\
\hline Nova Tebas & 2,4 D - $1.500 \mathrm{~m}$ de culturas orgânicas \\
\hline Terra Boa & $\begin{array}{l}\text { 2,4 D - Aplicação entre agosto e maio e } \\
5.000 \mathrm{~m} \text { do perímetro urbano }\end{array}$ \\
\hline Uraí & 2,4 D - Todo o município \\
\hline Wenceslau Braz & $\begin{array}{l}\text { 2,4 D - } 500 \mathrm{~m} \text { de recursos hídricos } \\
3.000 \mathrm{~m} \text { de culturas sensíveis" }\end{array}$ \\
\hline Cafelândia & $\begin{array}{l}\text { Capina química - } 200 \mathrm{~m} \text { do perímetro } \\
\text { urbano }\end{array}$ \\
\hline Paranaguá & Capina química - Zona urbana \\
\hline Sarandi & $\begin{array}{l}\text { Capina química - Somente produtos não } \\
\text { agrícolas na área urbana }\end{array}$ \\
\hline Guarapuava & $\begin{array}{l}\text { Inseticida - Distribuição, venda e } \\
\text { comercialização }\end{array}$ \\
\hline $\begin{array}{l}\text { Três Barras do } \\
\text { Paraná }\end{array}$ & $\begin{array}{l}\text { Inseticida - Área entorno do perímetro } \\
\text { urbano (cinturão verde) }\end{array}$ \\
\hline
\end{tabular}

Dois municípios apresentam leis proibitivas em relação aos inseticidas, Guarapuava proíbe a distribuição, venda e comercialização do carbamato Aldicarb e organofosforados, conhecidos popularmente por "chumbinho". Três Barras do Paraná não especifica os ingredientes ativos ou marcas comerciais, apenas restringe o uso de inseticidas na área ao entorno do perímetro urbano, denominada como cinturão verde.

As 24 leis avaliadas com restrições quanto ao uso de produtos químicos são mais específicas em relação à Resolução SEIN n. 022/85, determinando produtos comerciais e/ou moléculas restringidos nos municípios. Além disso, foram encontradas três leis que especificam períodos do ano com proibição na utilização de agrotóxicos, o que leva em consideração as particularidades de cada município.

\section{Restrição à pulverização aérea}

Entre os municípios com leis restritivas à aplicação de agrotóxicos, nove apresentaram restrições à pulverização aérea. Os municípios de Altônia e Campo Magro proíbem a aplicação aérea de agrotóxicos em todo o seu território, enquanto Barra do Jacaré restringe apenas o uso aéreo de inseticidas. Quitandinha restringe a pulverização aérea na zona urbana. Os demais municípios (Borrazópolis, Cascavel, Corbélia, Santa Tereza do Oeste e Terra Boa) indicam distâncias mínimas a serem respeitadas. O município de Terra Boa se destaca pela proibição da aplicação aérea de herbicida 2,4-D nos meses de junho e julho a uma distância mínima de $10.000 \mathrm{~m}$ de culturas sensíveis como uva, algodão, hortaliças e árvores frutíferas em geral.

De modo geral, as leis municipais seguem as recomendações da legislação federal (Instrução Normativa MAPA no 2/08) e estadual referente aos agrotóxicos (RESOLUÇÃO SEIN no 022/85). Estes instrumentos legais indicam que a aplicação aérea de agrotóxicos deve ocorrer a uma distância mínima de 500 m adjacente a mananciais de captação de água para abastecimento de populações, núcleos populacionais, escolas, habitações e locais de recreação, e, de $250 \mathrm{~m}$ adjacentes a mananciais de água, moradias isoladas e agrupamento de animais e culturas suscetíveis a danos.

O município de Santa Tereza do Oeste apresenta uma distância de aplicação aérea de agrotóxico de $200 \mathrm{~m}$ de moradia isolada e agrupamento de animais e culturas sensíveis, $50 \mathrm{~m}$ inferior ao proposto pelas normativas estaduais e federais. Desse modo, não atendendo a legislação estadual.

\section{Restrição em áreas especiais}

As áreas especiais foram divididas em Área de Preservação Permanente (APP), Área de Proteção Ambiental (APA), além de áreas de manancial hídrico. De acordo com a lei no 12.651, de 2012, APP é uma "área protegida, coberta ou não por vegetação nativa, com função ambiental de preservar os recursos hídricos, a paisagem, a estabilidade geológica e a biodiversidade, facilitar o fluxo gênico de fauna e flora, proteger o solo e 
assegurar o bem-estar das populações humanas". A lei delimita as distâncias que compreendem a área de preservação de cursos d'água, rios, lagos, encostas, restingas, manguezais, chapadas e topos de morro (BRASIL, 2012).

A Área de Proteção Ambiental constitui o grupo das unidades de uso sustentável, e é definida pela lei no 9.985, de 2000, como uma "área extensa, com certo grau de ocupação humana, dotada de atributos abióticos, bióticos, estéticos ou culturais especialmente importantes para a qualidade de vida e o bem-estar das populações humanas". Seus objetivos básicos são "proteger a diversidade biológica, disciplinar o processo de ocupação e assegurar a sustentabilidade do uso dos recursos naturais" (BRASIL, 2000).

Os municípios de Piraquara e Ponta Grossa indicam restrição de aplicação de agrotóxicos nas áreas de preservação permanente (APP). Irati, além de restringir o uso de agrotóxicos no perímetro urbano também proíbe o uso nas faixas de APP. Duas cidades (Paranavaí e Quatro Barras) apresentam leis que restringem a aplicação de agrotóxico nas áreas de proteção ambiental (APA). Em Paranavaí é nominada a APA Ribeirão das Araras, e em Quatro Barras, além da APA é proibido o uso em áreas de ocupação orientada e zona especial de indústria e serviços.

Em relação aos mananciais, no município de Arapongas é proibida a utilização de agrotóxicos somente nas proximidades de rios, córregos e lagoas e de fontes de captação de água para abastecimento público ou privado. O município de Astorga, além de proibir a utilização de agrotóxico na área urbana, também apresenta o mesmo artigo que Arapongas que proíbe agrotóxicos em mananciais hídricos.

A manutenção da qualidade dos recursos hídricos também foi bastante abordada nas leis com distâncias mínimas para uso de agrotóxicos na área urbana. Como exemplo temos os municípios de Adrianópolis, Cerro Azul, Foz do Iguaçu, Mangueirinha, Medianeira, Prudentópolis, Serranópolis do Iguaçu, Toledo, Tunas do Paraná e Umuarama que indicam as distâncias mínimas de aplicação de agrotóxicos dos recursos hídricos. Os municípios de Astorga e Irati também apresentaram leis restritivas, porém sem especificação da distância mínima a serem respeitadas.

Além disso, o município de Tupãssi apresentou uma lei ordinária que proíbe a circulação de implementos agrícolas com agrotóxicos em vias urbanas e rurais povoadas, e próximas de mananciais hídricos, reservas florestais e ecológicas. No entanto, a lei não faz menção sobre a utilização dos agrotóxicos, nem distâncias mínimas a serem adotadas.

\section{CONCLUSÕES}

Dos 399 municípios que compõe o estado do Paraná, 100 municípios possuem legislações que restringem ou proíbem o uso de agrotóxicos. Isso indica que aproximadamente $75 \%$ dos municípios não apresentam dispositivo legal sobre a aplicação de agrotóxicos. Por isso, a Resolução Estadual SEIN n022/85 é importante para nortear os municípios que não possuem leis sobre o tema, bem como os que não especificam distâncias mínimas para aplicação de agrotóxicos em seu território. A resolução contribui para auxiliar no uso adequado de agrotóxicos, de maneira a minimizar o uso indiscriminado e os impactos gerados ao meio ambiente e a saúde.

Dentre as 103 leis restritivas e proibitivas encontradas, 65 leis restringem o uso de agrotóxicos no perímetro urbano e rural, 24 proíbem o uso de algum tipo de agrotóxico específico, 9 restringem a pulverização na modalidade aérea, 4 proíbem o uso de agrotóxicos em áreas especiais (APA e APP), 1 lei restringe somente a aplicação próxima à recursos hídricos e 1 lei proíbe a circulação de implemento agrícola contendo agrotóxico no município.

Percebe-se o aumento do número de municípios que de alguma forma procuram formular legislações que complementem as leis federais e estaduais ao longo dos anos, visando restringir ou proibir a utilização de agrotóxicos.

\section{AGRADECIMENTOS}

Os autores agradecem à Coordenação de Aperfeiçoamento de Pessoal de Nível Superior (CAPES) pela bolsa de mestrado do primeiro autor, à Fundação Araucária pela bolsa de doutorado da terceira autora e o CNPq pela bolsa de produtividade de pesquisa do quarto autor.

\section{REFERÊNCIAS BIBLIOGRÁFICAS}

AGROFIT. Sistema de registro de agrotóxicos do Ministério da Agricultura. Disponível em: http://agrofit.agricultura.gov.br/ agrofit_cons/principal_agrofit_cons

BRASIL. Constituição Federal. Brasil, 1988. Disponível em: http://www.planalto.gov.br/ccivil_03/constituicao/constituicao. htm

BRASIL. Decreto 24.114, de 12 de abril de 1934. Aprova o regulamento de defesa sanitária vegetal. Brasil, 1934. 
BRASIL. Lei Federal no 7.802 de 11 de julho de 1989. Dispõe sobre a pesquisa, a experimentação, a produção, a embalagem e rotulagem, o transporte, o armazenamento, a comercialização, a propaganda comercial, a utilização, a importação, a exportação, o destino final dos resíduos e embalagens, o registro, a classificação, o controle, a inspeção e a fiscalização de agrotóxicos, seus componentes e afins. Brasília, 1989. Disponível em: http://www.planalto.gov.br/ccivil_03/leis/l7802.htm

BRASIL. Lei 9.974, de 6 de junho de 2000. Altera a Lei no 7.802, de 11 de julho de 1989, que dispõe sobre a pesquisa, a experimentação, a produção, a embalagem e rotulagem, o transporte, o armazenamento, a comercialização, a propaganda comercial, a utilização, a importação, a exportação, o destino final dos resíduos e embalagens, o registro, a classificação, o controle, a inspeção e a fiscalização de agrotóxicos, seus componentes e afins, e dá outras providências. Brasil, 2000. Disponível em: http://www.planalto.gov.br/ccivil_03/leis//9974.htm

BRASIL. Lei 9.985, de 18 de julho de 2000. Regulamenta o art. 225, § 10, incisos I, II, III e VII da Constituição Federal, institui o Sistema Nacional de Unidades de Conservação da Natureza e dá outras providências. Brasil, 2000. Disponível em: https://www.planalto.gov.br/ccivil_03/leis/I9985.htm

BRASIL. Decreto 4.074, de 04 de janeiro de 2002. Regulamenta a Lei no 7.802 , de 11 de julho de 1989, que dispõe sobre a pesquisa, a experimentação, a produção, a embalagem e rotulagem, o transporte, o armazenamento, a comercialização, a propaganda comercial, a utilização, a importação, a exportação, o destino final dos resíduos e embalagens, o registro, a classificação, o controle, a inspeção e a fiscalização de agrotóxicos, seus componentes e afins, e dá outras providências. Brasil, 2002. https://www.planalto.gov.br/ccivil_03/decreto/2002/d4074.ht

$\mathrm{m}$

BRASIL. Instrução normativa no 2, de 03 de janeiro de 2008. Aprovar as normas de trabalho da aviação agrícola, em conformidade com os padrões técnicos operacionais e de segurança para aeronaves agrícolas, pistas de pouso, equipamentos, produtos químicos, operadores aeroagrícolas e entidades de ensino, objetivando a proteção às pessoas, bens e ao meio ambiente, por meio da redução de riscos oriundos do emprego de produtos de defesa agropecuária, e ainda os modelos constantes dos Anexos I, II, III, IV, V e VI. Brasília, 2008. Disponível em: https://www.gov.br/agricultura/pt-br/assuntos/insumosagropecuarios/insumos-agricolas/agrotoxicos/arquivos/in2.pdf

BRASIL. Lei no 12.651, de 25 de maio de 2012. Dispõe sobre a proteção da vegetação nativa; altera as Leis nos 6.938, de 31 de agosto de 1981, 9.393, de 19 de dezembro de 1996, e 11.428, de 22 de dezembro de 2006; revoga as Leis nos 4.771, de 15 de setembro de 1965, e 7.754, de 14 de abril de 1989, e a Medida Provisória no 2.166-67, de 24 de agosto de 2001; e dá outras providências. Brasília, 2012. Disponível em: http://www.planalto.gov.br/ccivil_03/_ato2011-2014/2012/lei/ I12651.htm

COSTA, M.F. Tecnologia de aplicação de defensivos agrícolas. Cuiabá: UFMT, 2009.

EISFELD, R.L. NASCIMENTO, F.A.F. Mapeamento dos plantios florestais do estado do Paraná - Pinus e Eucalyptus. Curitiba: IFPR, 2015. Disponível em: http://www.florestasparana.pr.
gov.br/arquivos/File/Mapeamento/Publicacao_Mapeamento_Si te_02.pdf

IBAMA - INSTITUTO BRASILEIRO DO MEIO AMBIENTE E DOS RECURSOS NATURAIS RENOVÁVEIS. Relatórios de comercialização de agrotóxicos. 2019. Disponível em: http://www.ibama.gov.br/agrotoxicos/relatorios-de-comercializ acao-de-agrotoxicos

IBGE - INSTITUTO BRASILEIRO DE GEOGRAFIA E ESTATÍSTICA. Cidades e Estados: Paraná. IBGE, 2020. Disponível em: https://www.ibge.gov.br/cidades-e-estados/pr.html

IPARDES - INSTITUTO PARANAENSE DE DESENVOLVIMENTO ECONÔMICO E SOCIAL. Indicadores de desenvolvimento sustentável por bacias hidrográficas do Estado do Paraná. Paraná, 2017. Disponível em: http://www.ipardes.pr.gov.br/IDS/index.php/IDS2017/issue/vie $w / 1$

PARANÁ. Lei 7.827, de 29 de dezembro de 1983. Dispõe que a distribuição e comercialização no território do Estado do Paraná, de produtos agrotóxicos e outros biocidas, ficam condicionadas ao prévio cadastramento perante a Secretaria de Agricultura e Secretaria do Interior e adota outras providências. Paraná, 1983. Disponível em: http://www.iap.pr.gov.br/arquivos/File/ Legislacao_ambiental/Legislacao_estadual/LEIS/LEI_ESTADUAL_ 7827_1983.pdf

PARANÁ. Resolução SEIN no 022, de 05 de julho de 1985. Regula a poluição do meio ambiente por agrotóxicos e biocidas e dá outras providências. Paraná, 1985. Disponível em: http://celepar7.pr.gov.br/sia/atosnormativos/form_cons_ato1.a sp?Codigo $=1687$

PARANÁ. Resolução SESA no 446, 08 de novembro de 2016. Dispõe sobre a proibição de utilização de mecanismos para controle vetorial por meio de dispersão de agrotóxicos por aeronaves em áreas urbanas no estado do Paraná. Paraná, 2016. Disponível em: https://www.legisweb.com.br/legislacao/ ?id=331161 